\title{
A dança como prática corporal nas academias: multiplicidade de sentidos
}

\author{
Dance as body practice in gyms: multiplicity of meanings \\ La danza como práctica corporal en los gimnasios: multiplicidad de significados
}

\author{
Ana Carolina Marques da Silva ${ }^{a}$ (D) Adriana de Faria Gehres ${ }^{b}$ (D), \\ Iraquitan de Oliveira Caminhac
}

Palavras-chave:

Academias de

ginástica;

Dança;

Educação Física;

Ensino.

\section{Keywords:}

Gym academies;

Dancing;

Physical Education;

Teaching.

\begin{abstract}
RESUMO
O presente estudo objetivou compreender os sentidos produzidos com a prática da dança em academias de ginástica. Utilizou-se como abordagem teórica-metodológica a fenomenologia, valorizando as experiências descritas por professores e coordenadores através de entrevistas semiestruturadas, interpretadas por meio das análises ideográfica e nomotética. As análises permitiram-nos identificar múltiplos sentidos atribuídos à dança nas academias. Conclui-se que, embora haja uma centralidade da dança como exercitação e produto de consumo nas academias, as instituições, na figura dos(as) coordenadores(as) e professores(as), não só reconhecem suas características multifacetadas, como se constituem como atores para compor e produzir novos sentidos à sua prática.
\end{abstract}

\section{ABSTRACT}

This study aimed to understand the meanings produced with the practice of dance in gyms. Phenomenology was used as a theoretical-methodological approach, valuing the experiences described by teachers and coordinators through semi-structured interviews, interpreted through ideographic and nomothetic analyses. The analyzes allowed us to identify multiple meanings attributed to dance in gyms. It is concluded that, although there is a centrality of dance as exercise and consumption product in gyms, institutions, in the figure of coordinators and teachers, not only recognize its multifaceted characteristics, but also constitute themselves as actors that compose and produce new meanings to their practice.

\section{RESUMEN}

El presente estudio cubrirá las sensaciones que se producen con la práctica de la danza en la academia. Se utiliza como aproximación teórico-metodológica a la fenomenología, valorizando como experiencias descriptivas por profesores y coordinadores de entrevistas semiestructuradas, interpretadas por meio de análisis ideográfico y nomotético. Como analistas nos permiten identificar múltiples atributos atribuidos a la danza en el ámbito académico. Se concluye que, si bien la danza es una centralidad de la danza como ejercicio y producto de consumo en la academia, como instituciones, en la figura de (como) coordinadores (como) y profesores (como), no para reconocer sus características multifacéticas, como obras constituidas que componen y producen nuevas ideas sobre su práctica.

\footnotetext{
aUniversidade de Pernambuco, Universidade Federal da Paraíba, Programa Associado de Pós-Graduação em Educação Física (UPE/UFPB), Grupo de estudos socioculturais em Educação Física (GESEF/UPE). Recife, PE, Brasil.

bUniversidade de Lisboa, Faculdade de Motricidade Humana (FMHUL), Universidade de Pernambuco, Departamento de Educação Física (ESEF/UPE). Recife, PE, Brasil.

'Université Catholique de Louvain, Universidade Federal da Paraíba, Departamento de Educação Física, Programa Associado de PósGraduação em Educação Física (UPE/UFPB), Programa de Pós-Graduação em Filosofia. João Pessoa, PB, Brasil.
}

\author{
*Autor correspondente: \\ Ana Carolina Marques da Silva \\ E-mail: prof.anamarques@outlook.com
}

Recebido em 03 de fevereiro de 2021; aceito em 21 de julho de 2021. 


\section{INTRODUÇÃO}

O Global Report, da International Health, Racquet and Sportsclub Association, traduzido e publicado pela Associação Brasileira de Academias (ACAD), identificou que o Brasil é o segundo país com maior número de academias de ginástica (AC) no mundo, com a existência de quase 35.000 academias em todo o país e quase 10 milhões de alunos. (ACAD, 2018). Segundo Furtado $(2009,2007)$, espaços para a prática de exercícios físicos continuam se expandindo no país e, especificamente naqueles entendidos como $A C$, os serviços oferecidos tornam-se mais variados, numa tentativa de atender às demandas que emergem na sociedade.

A presente pesquisa resultou de inquietações da observação de uma crescente inserção de variados tipos de dança, anteriormente mais presentes em locais próprios para o seu ensino, nas AC, sendo oferecidas como mais uma prática corporal em sua grade de aulas. Esta realidade associa-se ao desenvolvimento das AC, que na última década fortalece-se pelo seu potencial lucrativo, com foco diretamente na acumulação de capital para superar concorrentes.

Nisto, instala-se um constante processo de racionalização da gestão, no qual teorias administrativas, financeiras, contábeis, de marketing, entre outras, dominam e orientam a organização dos ambientes das academias (iluminação, os setores, os materiais, a sonorização etc.) e com várias atividades para atender às demandas de seus clientes (nutrição, estética, exercitação). A oferta diversificada de práticas corporais torna-se uma estratégia de captação de clientes neste contexto "híbrido" que as academias assumem atualmente (Furtado, 2009).

Enfatiza-se assim a necessidade de um aprofundamento na compreensão da dança, como uma dessas práticas diversificadas, no ambiente das AC. A Educação Física e a dança, embora apontem para um entrelaçamento histórico no campo da educação, desde os movimentos ginásticos alemão e francês (Laban, 1978; Soares, 2005), e no âmbito da própria constituição da dança moderna americana (Alter, 1994), têm apresentado (in)tensas relações (Brasileiro, 2009) contemporaneamente. Mas o fato é que essas relações se configuram de uma maneira muito específica, não apenas nos espaços escolares, mas também em clubes, academias, escolas especializadas de dança, entre outros (Pereira e Hunger, 2006).

Muglia-Rodrigues e Correia (2013) reconhecem a multidimensionalidade da dança e suas constituições históricas, psicológicas, biológicas, antropológicas, sociológicas, e apontam para "uma conjugação efetiva dessa mesma multidimensionalidade para compor o espectro de saberes e habilidades previstas no âmbito da integração e assimilação dos processos de formação e da atuação profissional em Educação Física". (MugliaRodrigues e Correia, 2013, p. 96).
Ademais, Gehres (2008) expõe um olhar para a dança como multiplicidade de sentidos cujos significados são negociados a cada vivência/experimentação:

[...] A dança é, bem como outras formas de significação sócio-cultural, processo, e não produto, de criação/ recriação do homem e de seu mundo. [...] Assim entendida, uma dança é, em outras palavras, uma maneira de existência humana, a qual não pode ser aprisionada nos limites de uma descrição, demonstração ou apresentação - apesar da constância "aparente" da sua forma - pois se reconstrói a cada existencialização/execução nos corpos dos dançarinos e das dançarinas (Gehres, 2008, p. 07).

Assim, a presente pesquisa objetivou compreender os sentidos produzidos sobre a dança em AC situadas em Recife-PE, na perspectiva dos profissionais responsáveis, considerando que ela se constitui e precisa ser analisada nos diferentes campos de atuação em que se insere.

\section{MATERIAIS E MÉTODOS}

Como suporte teórico-metodológico, utilizou-se a abordagem Fenomenológica Hermenêutica (Bicudo, 2011; Merleau-Ponty, 2011).

Inicialmente, foram identificadas as AC que oferecem uma ou mais aulas de dança ${ }^{1}$, diferentemente daquelas modalidades frequentemente presentes nas $A C$ que instrumentalizam a dança como ginástica ${ }^{2}$. Os espaços foram selecionados considerando critérios sugeridos por autores que analisam as atuais configurações das $\mathrm{AC}$, situando-as como estabelecimentos que tendem a viabilizar diferentes tipos de atividades, incluindo aulas de dança (Furtado, 2007).

Com base em Furtado (2007), as AC foram selecionadas pela variedade de práticas corporais oferecidas, associadas ao hibridismo, presente em AC de médio a grande porte, que possuem como principais características estruturais a quantidade de alunos e o tamanho da área construída. O contato para identificação dos tipos de aulas nestes espaços foi realizado por telefone após a identificação em sites de busca na internet. Além disto, realizaram-se buscas em redes sociais popularmente utilizadas como veículos de comunicação e marketing das AC (Instagram e Facebook), em busca do maior número de sujeitos e instituições com diferentes perspectivas.

${ }^{1}$ Dança aqui se refere a formas de danças específicas que possuem ocorrência social fora das AC, como produções estéticas, éticas, poéticas e técnicas corporais e de ensino próprias, a exemplo do balé, dança de salão, danças populares, entre outras.

2 Geralmente associadas à melhoria de capacidades físicas/motoras, com nomenclaturas diversas como: fitdance, power dance, ritmos, zumba, etc. 
Apenas 4AC foram identificadas como dinamizadoras de aulas de dança no sentido investigado, sendo duas na zona norte e duas na zona sul de Recife-PE, com os seguintes tipos de dança: balé, jazz, dança de salão, dança do ventre e dança esportiva.

Em se tratando de um recorte na busca pelos sentidos produzidos com dança nas AC, com foco nas experiências e falas dos profissionais responsáveis, os participantes selecionados foram os coordenadores(as) responsáveis pelos setores que envolvem a dança, além dos(as) professores(as) dos tipos de dança em estudo. A escolha visou priorizar o contexto das aulas, considerando que a instituição, na figura dos(as) coordenadores(as) e os(as) professores(as), compõem cenários e realidades sobre o fenômeno, permitindonos revelar não somente aspectos subjetivos, mas intersubjetivos da produção de sentidos da dança nas AC.

Ao todo, 5 coordenadores(as) e 5 professores(as) foram selecionados(as):

a) Coordenador 1 (C1): masculino, 36 anos, licenciatura em Educação Física, sócio-proprietário e coordenador geral;

b) Coordenadora 2 (C2): feminino, 41 anos, licenciatura em Educação Física, coordenadora do setor de ginástica;

c) Coordenador 3 (C3): masculino, 49 anos, licenciatura em Educação Física, coordenador geral;

d) Coordenadora 4 (C4): feminino, 29 anos, licenciatura em Educação Física, professora de ginástica e coordenadora do setor de ginástica;

e) Coordenadora 5 (C5): feminino, 38 anos, licenciatura em Educação Física, coordenadora geral;

f) Professora 1(P1): feminino, 36 anos, ensino médio completo, formação em balé em estúdios, workshops e cursos de formação, com experiências com dança popular, dança portuguesa e hip-hop;

g) Professora 2 (P2): feminino, 35 anos, superior incompleto, experiência profissional em dança do ventre, formação em cursos e workshops;

h) Professora 3 (P3): feminino, 37 anos, licenciatura em Educação Física, pós-graduação em fisiologia do exercício, formação nacional e internacional em balé;

d) Professor 4 (P4): masculino, 48 anos, licenciatura em Educação Física, pós-graduação em dança e consciência corporal;

e) Professora 5 (P5): feminino, 40 anos,

fonoaudióloga, pedagoga, mestrado em Educação, especialista em patologia da linguagem, educação e desenvolvimento infantil e psicomotricidade, graduanda em licenciatura em Educação Física, formação em dança de salão.

\section{INSTRUMENTOS UTILIZADOS}

Para coleta dos dados foram realizadas entrevistas semiestruturadas entre janeiro e março de 2019. A inquirição dos(as) professores(as) foi viabilizada pelos(as) coordenadores(as) e todas aconteceram nas AC, gravadas em suporte de áudio e, posteriormente, transcritas. A pesquisadora, sempre que permitido, participava das aulas para uma aproximação inicial. Nas entrevistas buscou-se a compreensão do fenômeno, não somente pela descrição das falas, mas no exercício interpretativo, sem tempo limite predeterminado para a entrevista e seguindo um roteiro inicial de 15 questões.

Para os(as) coordenadores(as), história, organização do espaço e dados sobre a dança nas AC foram interrogados, e para os(as) professores(as), sua formação, experiência e atuação com dança, além da organização e planejamento das aulas nas AC.

Tomando como referência as análises sugeridas por Bicudo (2011), primeiramente foi empreendida a análise ideográfica: suspensão de qualquer crença, ideologia, concepção, teoria ou conhecimento prévio; leitura e análise das descrições apresentadas como relatos das experiências vividas; identificação das unidades de sentido; elaboração das unidades de significados; análise hermenêutica em busca da compreensão dos sentidos afirmados nas unidades de significado.

Todo esse trajeto compôs a busca por sentidos tomados individualmente, enredando-nos por meio das descrições ingênuas dos sujeitos, que revelam a estrutura de sua narrativa. Após isto, pôde ser realizada a análise nomotética, que significou transcender o aspecto individual obtido anteriormente, indicando o movimento de reduções por meio do entrelace das compreensões permitidas pela análise ideográfica, atentando para as convergências e divergências articuladas (Bicudo, 2011).

Ao analisar as narrativas, as seguintes temáticas foram articuladas: 1) A dança nas academias "significa"; 2) O papel da academia com relação à dança nas academias; 3) O papel do professor com relação à dança nas academias; 4) As circunstâncias do ensino da dança nas academias; 5) Visão de dança dos(as) coordenadores(as); 6) Visão de dança dos(as) professores(as); 7) O que/ como a dança na academia deveria ser; 8) Divergências e proximidades entre os diferentes tipos de dança nas academias; 9) Expectativa dos alunos na ótica dos profissionais responsáveis.

Estas temáticas foram reduzidas a apenas uma temática denominada por Bicudo (2011) como categoria aberta, pois não define a estrutura do ser por categorias, mas revela a categoria articulada no processo de investigação diante das análises ideográfica e nomotética, revelando possíveis horizontes de compreensão. Ou seja, as temáticas articuladas, quando reunidas, permitiram responder à interrogação central do estudo, a saber: os sentidos produzidos com a dança como prática corporal nas academias sob perspectiva dos profissionais responsáveis. 


\section{ASPECTOS ÉTICOS}

Os procedimentos adotados nesta pesquisa estão de acordo com o código de ética para pesquisas mediante a submissão ao Comitê de Ética da Universidade de Pernambuco ${ }^{3} \mathrm{e}$ a assinatura do Termo de Consentimento Livre e Esclarecido (TCLE).

\section{RESULTADOS}

\section{OS DIFERENTES SENTIDOS DA DANÇA COMO PRÁTICA CORPORAL NAS ACA- DEMIAS}

Gehres (2008), embora tenha estabelecido seu locus de estudo na educação básica, apontou que há uma multiplicidade de corpos produzidos com as danças e que estes são, ao mesmo tempo, objetos e sujeitos das relações existentes entre ensinar e aprender dança. Nesse estudo, a autora compreendeu que as danças e os corpos eram abertos, únicos, heterogêneos e principalmente múltiplos (Gehres, 2008). Em diálogo com esta pesquisa, mas considerando as diferenças apresentadas pelo locus de estudo e os diferentes sujeitos que experenciam as danças no espaço das AC, esta pesquisa apontou para os seguintes sentidos:
a) Dança como exercício físico/saúde;
b) Dança como atividade de lazer;
c) Dança como terapia;
d) Dança como coreografia;
e) Dança como socialização;
f) Dança como re-encenação;
g) Dança como espetáculo;
h) Dança como técnica corporal.

A dança como exercício físico revela-se nas narrativas tanto dos(as) professores(as), quanto dos(as) coordenadores(as), em todas as AC estudadas. O valor atribuído à perspectiva da saúde assumida no contexto das AC justifica esse ajuizamento com relação à dança, por ser um espaço que se destina à exercitação dos corpos. A vivência da dança nas AC como exercício físico associa-se às narrativas dos(as) coordenadores(as) ao determinarem que o objetivo da AC, ao introduzir a dança em seu espaço, concentra-se na possibilidade de melhorar aspectos como a força, a coordenação motora, o alongamento, o condicionamento físico, a capacidade cardiorrespiratória, entre outros. Os(as) professores(as) seguem a mesma argumentação, mas refletem como necessidade de firmar a dança como um importante componente daquele espaço, como se o exercício

${ }^{3}$ CAAE omitido para manutenção de anonimato. físico fosse um fator determinante para a valorização e permanência da dança na AC.

[...] e também depois de experimentar o exercício e sentir que às vezes, não colocando a sala de musculação pra trás, às vezes, em uma aula de balé você consegue sentir muito mais os músculos do que num treino. [...] porque é um exercício que mexe com o corpo e mexe com a mente também, que no outro dia a pessoa fica quebrada, sente todos os músculos e sente músculos que, às vezes, a musculação nem trabalha. (P1)

O objetivo é mostrar que, além das atividades de academia, existe o balé que é uma atividade física que proporciona o bem-estar. Não só aquela modalidade de academia que é direcionada a: "Ah! eu vou ter um corpo estético" só por causa da musculação. Não, o balé também pode oferecer isso! ( $\mathrm{P} 3$ )

A dança como exercício físico parece estar relacionada à possibilidade de promover uma atividade que atenda às necessidades sociais, como a busca por um corpo saudável, belo e esteticamente padronizado (Castro, 2003).

A dança como atividade de lazer está intimamente ligada à dança como terapia. Ambas aparecem nas narrativas de várias maneiras, refletindo sobre o significado da dança na vida das pessoas numa relação contínua entre corpo e mente. Surge como uma possibilidade de aula para pessoas que a buscam no seu tempo de "não trabalho", podendo vir a ser descanso, entretenimento e realização de uma atividade prazerosa para os(as) clientes.

Além disso, reconhece a realização de uma atividade que não se manifesta como contato profissionalizante (formação de bailarinos), tampouco rígido e disciplinar, que muitas vezes se encontra em escolas próprias para o ensino da dança. Ao contrário, estabelece um contato que propõe aos alunos o relaxamento, a despreocupação com as atividades diárias e a desaceleração da vida cotidiana. A P5 realiza a seguinte reflexão:

Mas a grande maioria, o perfil, são senhoras, são pessoas que muitas vezes têm a aula de dança como um momento de terapia, de descontração, esquecer os problemas. [...] E o objetivo é realmente socializar, confraternizar, promover uma atividade física, que esse momento de aula seja um momento de alegria na vida deles. (P5)

Neste momento, a P5 indica as aproximações entre a perspectiva do lazer com a terapia, ao associar a dança como uma forma de superação/distanciamento dos problemas diários, para além de um momento de divertimento e descontração. Percebe-se que na confluência entre as narrativas, hora ou outra, a relação bem-estar e saúde mental, como um modo de o ser humano se comunicar, expressar seus sentimentos e necessidades, aparecia como elemento para o 
planejamento e a realização das aulas. O P4 reforça isto, ao afirmar:

Eu acho que a dança tem uma necessidade hoje, que a gente vive a questão do receio, do medo, da ansiedade, aquela coisa assim. $O$ ser humano guarda muito os sentimentos pra si, e à medida que o aluno vem pra aula e consegue colocar isso pra fora, ele sai leve, ele sai renovado. Eu vejo dessa forma, a necessidade do ser humano colocar suas emoções pra fora. (P4)

Sobre a dança como coreografia, os(as) professores(as) indicavam que as aulas se estabeleciam na repetição de passos e gestos contínuos, com coreografias criadas pelos(a) professores(as) e executadas pelos(as) alunos(as). Contudo, estas não se associam às músicas e às "danças" amplamente consumidas nas AC e nas mídias em geral, como nas danças-ginásticas (zumba, fit dance, ritmos) (Thompson, 2011).

Embora não tenha sido um sentido que apareceu expressivamente nas falas dos depoentes, a dança como coreografia surge como experiência narrada que pode revelar a necessidade de adaptação dos(as) professores(as) frente ao contexto de dança-ginástica fortemente presente nos anos anteriores nas AC.

A dança como socialização nas falas dos(as) coordenadores(as) refere-se à possibilidade desta prática ser um espaço-tempo no qual as pessoas se reúnem e se mantêm, quase como numa sociedade viva dentro das AC, na aproximação de pessoas que possuem anseios, desejos e histórias de vidas semelhantes.

Entretanto, o cenário atual com foco na superação da alta rotatividade mercadológica faz com que os(as) coordenadores(as) atribuam a este convívio, fortalecido pelos laços afetivos e emocionais entre clientes e professores(as), um valor que se assenta na possibilidade deste se manter matriculado e principalmente envolvido e instigado a permanecer na $A C$, um valor comercial. As narrativas dos(as) professores(as), contudo, expressam uma preocupação maior em construir um ambiente de socialização como meio de produção dos sentidos de terapia e lazer, já citados anteriormente.

A dança como re-encenação associa-se, neste estudo, à possibilidade de quebra dos padrões estéticos, identificadas nas narrativas dos(as) professores(as) no que se refere à existência de um corpo predefinido para a prática de cada tipo de dança, de maneira mais expressiva no universo do balé. Não à toa, pois, ao longo da história do balé, observa-se uma exigência de certo biótipo e regras rígidas que não se limitam a bailarinos(as) profissionais, perpetuando-se no seu ensino e prática em escolas de dança, grupos e companhias (Moura, 2001).

As AC passam a ser um espaço onde os adultos vislumbram a possibilidade de dançar sem que seus corpos sejam questionados ou desqualificados como impróprios para a realização desta atividade. A re-encenação apresenta-se em Lepecki (2013) quando anuncia, em sua análise de alguns coreógrafos contemporâneos, criações que propõem a se "re-obrarem", dar corpo àquilo que já foram uma vez, não numa tentativa de reprodução de obras passadas, da maneira como foram executadas, mas da possibilidade e vontade de ser "tudo aquilo que não foi e que ainda pode vir a ser" (Lepecki, 2013, p. 120).

A re-encenação, conforme apontada pelo autor, permite questionar a relação que se estabelece nas AC com a dança, de que padrões corporais atuais e os vividos na infância e adolescência com a dança podem ser desafiados num processo de reencenação de corpos que dançam, sejam os corpos que já dançaram ou os corpos que sempre quiseram dançar e não se sentiam aptos e agora permitem-se re-encenar estas danças num corpo maduro, adulto. Pois o corpo é sempre "corpo-arquivo, porque formador e transformador de si mesmo e dos enunciados que o fazem, o delimitam mas que, por isso mesmo, o abrem para devires" (Lepecki, 2013, p. 120).

Os(As) entrevistados(as) sugerem que as danças nas AC podem colaborar para ressignificar e recriar a experiência da dança para adultos. As narrativas dos representantes de duas $\mathrm{AC}$ que oferecem as aulas de balé apresentam a re-encenação mencionada:

As meninas da manhã são meninas que muitas vezes não tiveram oportunidade de fazer o balé, não financeira que acredito que aqui não é o caso, mas a questão do biotipo. Porque eu fui irmã de bailarina, minha irmã era longilínea, magrinha, tinha todo o biotipo do balé. Já eu quis entrar numa escola de balé, eu fazia natação, mas quis fazer a escola de balé num clube, cheguei lá e a professora disse: "mas você não tem perfil pro balé não". [...] Aí esse trabalho é um resgate, eu acho que o balé principalmente da manhã é um resgate das pessoas, ou que fizeram e tiveram que parar, mas a grande maioria são pessoas que não tiveram a oportunidade de fazer balé, mas que hoje na vida adulta estão tendo essa experiência. (C2)

A gente percebeu que ao decorrer muita gente tinha muita vontade de fazer balé desde pequena e que de repente isso é um sonho que ficou muito reprimido na infância e ao decorrer do tempo com estudo, trabalho, faculdade, essas coisas, a pessoa vai colocando o que quer fazer em segundo plano. E foi uma coisa que deu certo acredito que por conta disso, que muitas pessoas tinham essa vontade um pouco frustradas (P1)

A re-encenação, portanto, diz respeito à liberdade de realizar aulas de dança sem que sejam descartadas por seus biotipos, a que $\mathrm{C} 2$ se refere, que predetemina quem deve ou não compor determinado espaço. Logo, as aulas nas AC, de acordo com professores(as) e coordenadores(as), possibilitam que os(as) clientes recoloquem os corpos em cena, numa outra cena e num outro local, espacial e temporal, facilitando com que as pessoas sintam-se à vontade para ocupar aquele espaço, atribuindo à dança este valor, da liberdade de pertencimento ou da possibilidade de vivenciar experiências corporais anteriormente não "permitidas". 
A dança como espetáculo está presente na AC2, na qual todas as aulas de dança que se apresentam no espaço, tanto para os adultos quanto para crianças e jovens, são transformadas em trabalhos coreográficos que são apresentados num espetáculo de dança ao final do ano. A C2 explica sobre esta iniciativa:

\begin{abstract}
A P3 trouxe isso pra cá. Trouxe o balé adulto tentando fazer esse resgate realmente do balé. Foi onde surgiu a ideia do primeiro festival de dança no primeiro ano da academia, que foi uma ideia da professora. [...] A dança na AC2 surgiu com esse meu incentivo de colocar outras aulas, outros tipos de professores, outras modalidades e ter esse fechamento no final. Eu acho que esse fechamento, esse festival... que é uma das atividades que tem mais sucesso aqui, dão esse empurrãozinho para que essa dança no clube seja muito forte. (C2)
\end{abstract}

A dança como espetáculo, na fala da coordenadora, é um meio de se vislumbrar a dança numa perspectiva artística, simbólica e apreciativa, e por isso a dança na AC2 se torna mais "forte" ao se associar diretamente à materialização deste espetáculo, ao expor ao público, que parece comparecer aos espetáculos (sucesso), as atividades que se realizam dentro das salas, o que acaba por colaborar para a materialização e continuidade da dança no espaço.

Por fim, a dança como técnica corporal remete-se a um corpo que se constrói para a dança, ou seja, para a atuação como dançarino(a) na aquisição e domínio da linguagem específica de uma determinada dança (Gehres, 2008), que os(as) tornem aptos para a dança como dançarinos(as) profissionais ou não com o intuito de ocupar palcos, festivais, mostras e todo este universo que compõe o cenário da dança. Esse sentido se produz, com os(as) coordenadores(as) e professores(as), juntamente com os sentidos anteriormente identificados da dança como exercício físico, do bem-estar físico e mental, da dança como lazer, despretensiosa à rigidez que geralmente se apresenta em escolas próprias para o ensino da dança.

Porpino (2018) aponta que, assim como qualquer outra manifestação artística e cultural, a dança exige um processo de aprendizado e aquisição de técnicas para sua realização. Logo, o processo de treinamento, desenvolvimento de técnicas, a repetição, são essenciais para que ocorra uma expressão nova, estética. Este aprendizado não necessariamente diz de uma atitude tecnicista e autoritária, mas "a necessidade de um aprendizado de um modo de fazer, que na dança pode ser traduzido como um modo de fazer poético" (Porpino, 2018, p. 125).

Ministrar aulas de dança nas AC, como técnica corporal, significou, para os(as) professores(as), tensionar com os seus contextos. Esse afrontamento gerou ações tanto de submissão e reprodução como de criação e produção de outras possibilidades. Algumas narrativas revelam as interpretações realizadas:
Porém, as alunas que não são regulares elas aparecem pra fazer uma aula experimental, aí acham que é uma aula mais dinâmica, como são as aulas que geralmente tem em academia, e acaba que é uma coisa muito técnica também. Então elas geralmente não ficam. Nas minhas aulas são poucas as que vão e ficam, geralmente elas vão e não voltam nunca mais. Porque eu até já tentei me adequar a essa questão da academia, até porque eu sei que dar aula em academia a pegada é diferente, mas eu não consigo, a minha pegada é muito técnica, então nem todo mundo fica. (P2)

Elas perceberam a necessidade de trabalhar um pouquinho técnica, daí veio a necessidade de criar essa outra aula chamada de body dance. Que é a construção de um corpo para a dança. Trabalhando flexibilidade, alongamento, consciência de posições de braço, de perna, de giro, como utilizar a escápula, a abordagem do pé no chão, caminhada, deslocamento e etc. [...] Até porque na primeira aula a intenção é a perda calórica, eu não posso parar pra tá ensinando o movimento, eu explico rapidamente esse movimento. (P4)

Na primeira narrativa, P2 expressa sua dificuldade em se adequar às especificidades das aulas projetadas nas $A C$, em detrimento de sua experiência profissional que se expressa no ensino a partir do desenvolvimento da linguagem da dança do ventre ${ }^{4}$. Já a segunda narrativa revela uma particularidade da $A C 3$, que foi a criação de uma aula extra com vistas ao aprimoramento técnico das alunas na dança esportiva ${ }^{5}$, já que esta estava sendo incorporada como exercício físico e coreografia, num formato que se assemelha às configurações da dança como ginástica/exercício, sem espaço para o desenvolvimento da linguagem específica da dança. Nisto, a AC3 amplia os horários das aulas para suprir as diferentes perspectivas em que a dança se apresenta, nas quais a técnica corporal aparece quase como uma obrigatoriedade para a continuação das aulas de maneira mais efetiva.

Diante disto, reflete-se sobre de que forma a dança chega às $A C$ e de como se reconfigura. A dinâmica existente entre os produtos midiáticos e as danças acaba por se reproduzir nos espaços das AC. De que maneira, portanto, a dança vem sendo naturalizada/ou desnaturalizada nas AC?

Embora incorporadas em seu sentido artístico (técnico, estético, poético), as danças analisadas no presente estudo estão constantemente estabelecendo um diálogo com o conceito da AC, a partir das relações com a ginástica e das aulas de dança que se propagam

${ }^{4}$ A caracterização da dança do ventre como forma de dança específica pode ser encontrada em Bencardini (2002).

${ }^{5}$ Sobre dança esportiva e sua caracterização, ver https://www.worlddancesport.org/ 
como efeito dos processos mercadológicos e midiáticos que perpassam esses espaços. As danças que aparecem neste estudo, no entanto, implicam contextos culturais e sociais historicamente específicos, constituídos como expressão e arte do movimento e não como exercitação. Ao abrigar estas aulas nas AC, precisa-se considerar a multiplicidade de sentidos que se apresentam e que puderam ser identificados nas narrativas dos(as) professores(as) e coordenadores(as).

Em outras palavras, a análise das experiências vividas e narradas permite afirmar que os sentidos produzidos com as danças nas $\mathrm{AC}$ se apresentam de múltiplos, e são reconfigurados pelos sujeitos entrevistados, inclusive a partir de suas vivências anteriores às da AC. Por isso, os(as) professores(as) nunca atuam de maneira única, assim como os(as) coordenadores(as) ressignificam a dança, pela proposta de atuação do espaço, pelas necessidades expostas pelos(as) clientes, ou pela própria experiência vivida que se reflete em sua compreensão de dança, valorização ou desvalorização desta prática corporal em detrimento de outras atividades das AC.

A identificação dos sentidos atribuídos por estes sujeitos que são mundo-vivido-dança nas academias e os significados revelados pelas narrativas permitem propor a construção de um pensamento próprio para o ensino da dança nas AC, ou pelo menos um pontapé para pesquisas em profundidade sobre estes contextos.

\section{CONCLUSÃO}

A compreensão dos sentidos da dança na perspectiva dos profissionais responsáveis apontou para muitos sentidos: nas AC ela se apresenta de maneira multifacetada, onde os sentidos interpretados e os significados atribuídos entrelaçam-se e reconfiguram-se cotidianamente.

Além disto, evidencia-se que a presença das danças nas $\mathrm{AC}$ está intimamente relacionada às danças na mídia. (Tomazzoni, 2013). Toda a visibilidade e espetacularização do cenário midiático acaba constituindo a dança nos espaços das AC, primeiramente pelo sentido de festa, alegria e diversão atribuída, mas também pela construção de uma ideia de diversificação de danças produzidas para todos(as), numa governamentalidade de que todos(as) devem entrar na dança na contemporaneidade.

Nisto, enfatiza-se, a partir dos sentidos atribuídos por coordenadores(as) e professores(as), a necessidade de considerar as diferentes perspectivas da dança como fenômeno, para que sua multiplicidade não se esvazie quando inserida nas AC, haja vista a relação de efemeridade e hibridez nestes espaços que afetam a dança como fenômeno polissêmico.

Ademais, faz-se necessário uma crescente busca pelo aprofundamento das discussões sobre dança, sobretudo em espaços variados de atuação do profissional de Educação Física. A presente pesquisa pode apresentar limites teóricos e metodológicos, portanto discussões mais aprofundadas e diferentes instrumentos de pesquisa para que o desenvolvimento de novas investigações sejam formulados.

\section{FINANCIAMENTO}

O presente trabalho foi realizado com apoio da Coordenação de Aperfeiçoamento de Pessoal de Nível Superior - Brasil (CAPES) - Código de Financiamento 001.

\section{CONFLITOS DE INTERESSES}

Os autores declaram não haver conflitos de interesse.

\section{REFERÊNCIAS}

ACAD: Associação Brasileira de Academias. Mercado mundial do fitness: principais players e mudanças no top ten [internet]. Rio de Janeiro: Associação Brasileira de Academias; 2018 [citado em 2021 Jul 21]. Disponível em: https://acadbrasil.com.br/wp-content/uploads/2019/03/ edicao-82.pdf

Alter J. Dancing and mixed midia: early twentieth-century modern dance theory in text and photography. New York: Peter Lang; 1994.

Bencardini P. Dança do ventre: ciência e arte. São Paulo: Texto Novo; 2002.

Bicudo MAV. Pesquisa qualitativa segundo a visão fenomenológica. São Paulo: Cortez; 2011

Brasileiro LT. Dança - Educação Física: (in) tensas relações [tese]. Campinas: Faculdade de Educação, Universidade Estadual de Campinas; 2009.

Castro AL. Culto ao corpo e sociedade. Mídia, estilos de vida e cultura do consumo. São Paulo: Annablume/Fapesp; 2003.

Furtado RP. Do fitness ao wellnes: os três estágios de desenvolvimento das academias de ginástica. Pensar a Prática 2009;12:1-11.

Furtado RP. O não-lugar do professor de Educação Física em academias de ginástica [dissertação]. Goiânia: Faculdade de Educação, Universidade Federal de Goiás; 2007.

Gehres AF. Corpo-dança-educação na contemporaneidade ou da construção de corpos fractais [tese]. Lisboa: Faculdade de motricidade humana - Dança, Universidade Técnica de Lisboa; 2008.

Laban RO. Domínio do movimento. São Paulo: Summus; 1978.

Lepecki A. Planos de composição: dança, política e movimento. In: Raposo P, Cardoso VZ, Dawsey JC, Fradique T, editores. A terra do não-lugar: diálogos entre a antropologia e performance. Florianópolis: Editora UFSC; 2013.

Merleau-Ponty M. Fenomenologia da percepção. 4. ed. São Paulo: Martins Fontes; 2011.

Moura KCF. Essas bailarinas fantásticas e seus corpos maravilhosos: existe um corpo ideal para dança? [Dissertação]. Campinas: Universidade Estadual de Campinas, Faculdade de Educação; 2001.

Muglia-Rodrigues B, Correia W. Produção acadêmica sobre dança nos periódicos nacionais de Educação Física. Rev Bras Ed Fis e Esporte 2013;27(1):91-9. http://dx.doi. org/10.1590/S1807-55092013005000002. 
Pereira ML, Hunger, DACF. Dança e Educação Física no Brasil: questões polêmicas. Revista Digital, Buenos Aires 2006;11(96).

Porpino KO. Dança é Educação: interfaces entre corporeidade e estética. 2. ed. Natal: EDUFRN; 2018.

Soares CL. Imagens da educação no corpo: estudo a partir da ginástica francesa no século XIX. 3. ed. Campinas: Autores Associados; 2005.
Thompson WR. Pesquisa mundial de tendências de fitness para 2012. ACSM's Health Fit J 2011;15:9-18. http://dx.doi. org/10.1249/FIT.0b013e31823373cb.

Tomazzoni AR. Lições da dança na mídia: perspectivas na cena contemporânea. In: Mozzini C, Ferraz W, organizadores. Estudos do corpo: encontros entre artes e educação. Porto Alegre: INDEPIn; 2013. 